\title{
How gender disparities drive imbalances in health care leadership
}

\author{
This article was published in the following Dove Press journal: \\ Journal of Healthcare Leadership \\ 16 November 2011 \\ Number of times this article has been viewed
}

\author{
Mary Ann Keogh Hoss' \\ Paula Bobrowski \\ Kathryn J McDonagh ${ }^{3}$ \\ Nancy M Paris ${ }^{4}$ \\ 'Health Services Administration, \\ Eastern Washington University, \\ College of Business and Public \\ Administration, Spokane, WA, USA; \\ ${ }^{2}$ College of Liberal Arts, Auburn \\ University, Auburn, AL, USA; \\ ${ }^{3}$ Executive Relations, Hospira Inc, \\ Lake Forest, IL, USA; ${ }^{4}$ Georgia Center \\ for Oncology Research and Education, \\ Atlanta, GA, USA
}

\begin{abstract}
Low female representation in US hospital chief executive officer positions has persisted for decades. This article addresses gender disparity in professional development, the rationale for gender differences, and practical strategies to address this imbalance. The health care workforce consists of $75 \%$ women, but according to two recent surveys, ie, a state survey and a survey of the top 100 US hospitals, women hold only about $12 \%$ of chief executive officer positions in US hospitals. Significant and dedicated efforts by both individuals and organizations are necessary to rectify this imbalance.
\end{abstract}

Keywords: gender, imbalance, leadership, United States, hospitals

\section{Introduction}

A myriad of influences have shaped the leadership opportunities available to women in health care over time. This article addresses evidence of gender disparity in professional development, the rationale for gender differences, and practical strategies to address the gender imbalances that continue to exist today in health care leadership.

Women as caregivers and leaders have positively impacted health care through the ages, with pioneers such as Florence Nightingale, Dorothea Dix, Margaret Sanger, Elizabeth Seton, and Elisabeth Kubler-Ross. These women leaders had to overcome the barriers and stereotypes that persist about women and their leadership capabilities. ${ }^{1}$

These female pioneers were the exception in a world of male physicians and scientists. Nightingale's revolutionary changes in the British health care system during the Crimean War were nothing short of heroic in the face of resistant British military leaders. "The courage and vision that Nightingale embraced is the same type of fortitude needed to face the future in health care today."2 Many of her principles of infection control, advocacy for patients, nutrition, and hospital organizational structures remain relevant today. Although we know Nightingale best as the founder of modern nursing, she was also in many ways the first hospital administrator and the architect of the modern hospital. ${ }^{3}$

Over the centuries, healing has been the prerogative of women, including the medicinal use of herbs, healing techniques, and midwifery. The female lay healer with all her traditional wisdom was eventually eliminated by professional male physicians as medicine became a commodity and a source of wealth in itself. ${ }^{4}$ This transition of healing becoming a business resulted in a predominantly male enterprise. This pattern continued as management of health care organizations developed into professional roles, with the traditional practice of female nurses managing hospitals shifting to male hospital administrators.
Correspondence: Mary Ann Keogh Hoss Health Services Administration, Eastern Washington University, College of Business and Public Administration, 668 N Riverpoint Blvd, Spokane, WA 99202-1677, USA

$\mathrm{Tel}+\mathrm{I} 509828$ I245

Fax + I 509828 I275

Email mhoss@ewu.edu 
Women have navigated the male-dominated structures of health care for centuries and continue to face challenges in asserting their leadership and influence. Despite the fact that today women make up over three-quarters of the health care workforce and are the largest consumers of health care, they remain significantly under-represented in the board room and chief executive officer (CEO) positions. For instance, women represent only $12 \%$ of CEOs, a percentage that has not changed much in the last decade. ${ }^{5}$ Despite their many contributions to health care, women continue to experience career advancement problems, and we explore these problems further here.

\section{Transforming views of women leaders from a historical perspective}

The first definitions of leadership emerged in the early 1800s. These definitions reflected male domination in society, first in the realm of politics and subsequently in corporations. Leadership theory was first derived as the Great Man Theory, which says that the personal attributes of great men determined the course of history. ${ }^{6}$ The Great Man Theory led to studies in the 1940s focusing on leadership trait theories that delineated the male characteristics needed for success. Researchers studied trait characteristic theories from a male perspective, because women occupied only about $4 \%$ of management roles at the time. ${ }^{7}$ Male-dominant traits composed the model of leadership, while the caring, nurturing, and relationship-building characteristics attributed to women were not associated with ability to lead. The cultural bias toward the "male as manager" pervades not only studies conducted in the US, but also ones from Germany, the UK, China, and Japan. According to Schein, "Despite the many historical, political, and cultural differences that exist among these five countries, the view of women as less likely than men to possess requisite leadership characteristics continues to be a commonly held belief among male management students around the world".

Researchers on leadership theory eventually rejected the idea that traits alone are enough to explain effective leadership; subsequently, they questioned the concept that leaders are born, not made. Researchers began to investigate behaviors that people could teach and learn. As a result of these investigations, researchers identified numerous behavior-based styles, such as democratic, autocratic, and laissez faire. ${ }^{9}$ The concept of employee versus productionoriented managers led to the development of a twodimensional typology. This typology assessed leadership behavior on dynamics related to concern for people and concern for production. ${ }^{10}$ Behavioral theories that were broader in perspective gained prominence in the 1960s during the technological revolution, yet those theories did little to increase the number of women in management. Women who entered the workforce held positions at the lower to middle levels of management; overall, women in management remained stagnant at about $16 \%$ of the workforce well into the 1970 s. ${ }^{11}$

It was not until the 1990s that researchers began to look at gender differences in leadership. Jogulu and Wood argue that gender studies started to raise the profile of women in management, yet these studies did little to shift the underlying belief that men are more likely to possess the characteristics required to be effective leaders. ${ }^{12}$ In their meta-analysis of 54 gender studies, Eagly and Karau concluded that men more often emerged as task-oriented leaders, while women were found to engage in behaviors that demonstrated agreement with others. Eagly and Karau also found that women emerged as social leaders more frequently than men. Researchers eventually started to link female characteristics with effective leadership. Simultaneously, the number of women in management increased, and career advancement for women started to become an accepted norm in the workplace. ${ }^{13}$

In the 1990s, researchers began to study the dynamics of leadership effectiveness by focusing on transactional versus transformational leadership. Transformational leadership emphasizes shared influence throughout an organization in contrast with a traditional model of power and authority concentrated in one individual at the top of the organizational hierarchy. Transformational leaders establish collegial relationships based on trust and confidence, serve as role models whom staff members emulate, and mentor their employees. Researchers discovered a strong correlation between leadership effectiveness and transformational leadership. ${ }^{14,15}$ Curiously, researchers on leadership theory found the attributes of transformational leadership to be more closely aligned to female characteristics. Also, they found that women were more likely to be friendly, pleasant, interested in other people, expressive, and socially sensitive. ${ }^{16}$ Furthermore, Bass found that transformational leaders are more successful and have been found to produce better financial results than transactional leaders. ${ }^{17}$ A meta-analysis of studies measuring the effectiveness of leaders revealed higher overall effectiveness for transformational leaders. This study also indicated that women are more inclined toward transformational leadership and have generally effective leadership styles. Men, on the other hand, have styles that are only somewhat effective or styles that hinder effectiveness. ${ }^{18}$ Table 1 describes these styles. 
Table I Comparison of leadership styles

\section{Transformational \\ Demonstrates qualities that motivate, respect and pride from association with him/her \\ Communicates values, purpose and importance of organization's mission \\ Exhibits optimism and excitement about goals and future states \\ Examines new perspectives for solving problems and completing tasks Focuses on development and mentoring of followers and attends to their basic needs Bull. 2003;|29:569-59|. \\ Is higher education playing a role in the imbalance of women in leadership positions?}

Eagly AH, Johannesen-Schmidt MC, van Engen ML. Transformational, transactional and laissez-faire leadership styles: A meta-analysis comparing women and men. Psychol

The numbers of women pursuing baccalaureate and post baccalaureate degrees continues to increase. Figures 1 and 2 demonstrate that that gap between men and women college graduates will continue to widen in favor of women. Figure 3 shows the fields in which the most master's degrees are awarded to women. Health professions and related clinical sciences rank at the top. ${ }^{19}$

\section{Transactional}

Provides rewards for satisfactory performance by followers

Attends to followers' mistakes and failures to meet standards Waits until problems become severe before attending to them and intervening

However, the increased number of women with degrees does not seem to have altered views of women as leaders. A recent study of college-age women did not reveal that broad-based social progress has had an effect on the views of women in leadership roles. Much like their counterparts during the 1990s, college women of today who aspire to become leaders continue to feel that their abilities and talents are not effectively judged against their male counterparts, a feeling that results in a sense of insecurity and uncertainty and which, in turn, reinforces both traits. The analysis shows that

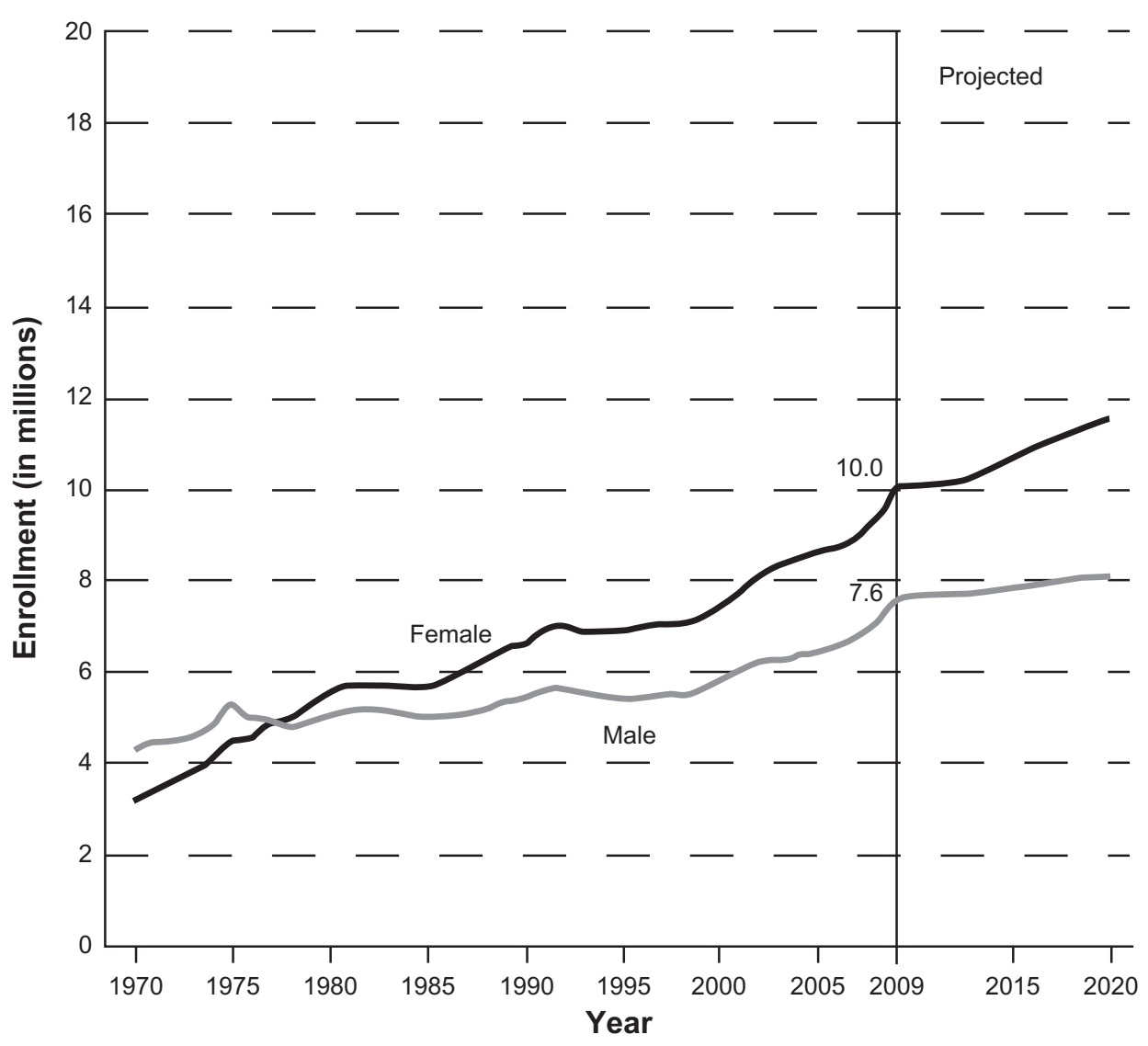

Figure I Actual and projected baccalaureate enrollment in degree-granting institutions, by gender for autumn 1976-2020.

Source: U.S. Department of Education, National Center for Education Statistics, 2008-09 Integrated Postsecondary Education Data System, Fall 2009. 


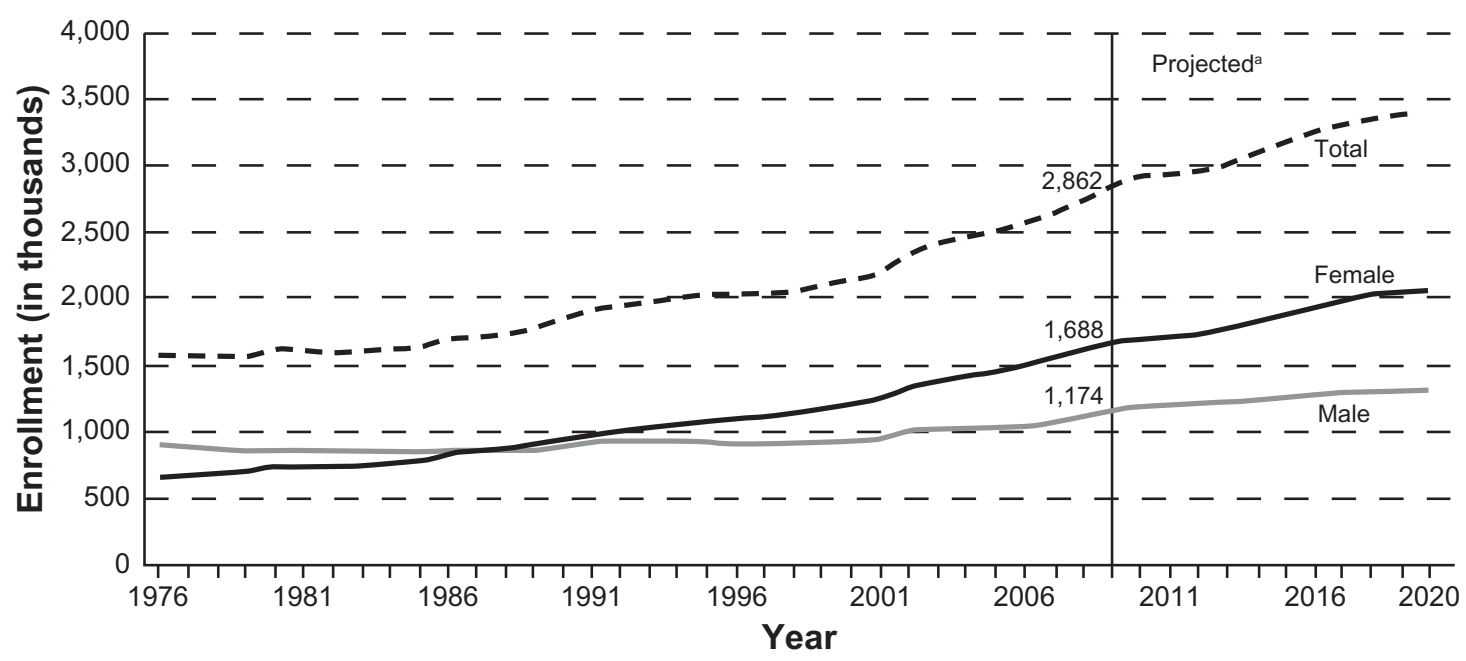

Figure 2 Actual and projected post-baccalaureate enrollment in degree-granting institutions, by gender, autumn $1976-2020$.

Note: Postbaccalaureate enrollment is the number of students with a bachelor's degree who are enrolled in graduate-level of first-professional programs. For more information on the Integrated Postsecondary Education Data System (IPEDS), see supplemental note 3.

Source: U.S. Department of Education. National Center for Education Statistics, Higher Education General Information Survey (HEGIS)," Fall Enrollment in Colleges and Universities" surveys, 1967 through 1985; 1986 through 2009 Integrated Postsecondary Education Data System, "Fall Enrollment Survey" (iPEDS-EF:86-99), and Spring 200I through 200I through spring 2010; and Enrollment in Degree-Granting Institutions Model, 1980-2009.

aProjections are based on reported data through 2009. The most recent year of actual data is 2009 , and 2020 is the last year for year for which projected data are available. For more information on projections. see NCES 20I I-026. Data for 1999 were imputed using alternative procedures. For more information, see NCES 200I-083, appendix E.

male domination is not a thing of the past, and it continues to play a crucial role in the consequences of discrimination. When male participants tried to dominate or assume unofficial leadership roles, participants felt less secure, had lower self-esteem, and experienced less overall respect. ${ }^{20}$

Talented employees are critical to the efforts of organizations to be competitive. ${ }^{21}$ Because women now outperform their male counterparts in higher education, talent in the US will increasingly stem from the female population. A number of researchers have indicated that organizations now require leaders who are more "relational-oriented, nurturing, and caring", ie, styles associated with women and different from the more aggressive, competitive, and task-oriented leadership style associated with men..$^{22,23}$ Despite these views, women

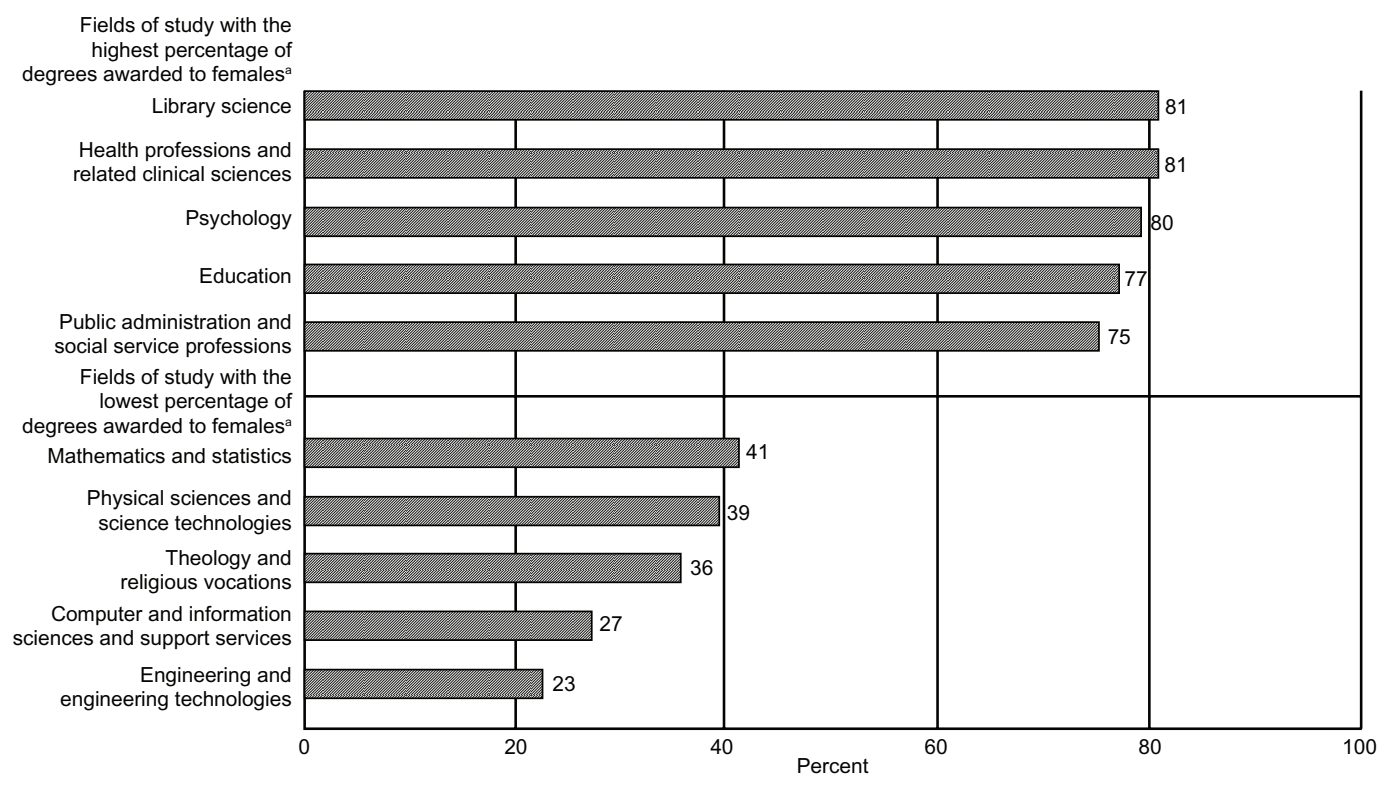

Figure 3 Percentage of master's degrees awarded to females by degree-granting institutions in selected fields of study for the 2008-2009 academic year. Note: For more information on fields of study for postsecondary degrees, see supplemental note 9 . For more information on the classification of postsecondary education institutions, see supplemental note 8. For more information on the Integrated Postsecondary Education Data System (IPEDS), see supplemental note 3.

Source: U.S. Department of Education, National Center for Education Statistics, 2008-09 Integrated Postsecondary Education Data System, Fall 2009. a Of the 20 fields of study in which the most master's degrees were awarded in 2008-09. 
continue to be sorely under-represented in senior leadership positions worldwide. According to the 2008 Catalyst Census of Women Corporate Officers and Top Earners of the Fortune 500 in the US, women held just $15.2 \%$ of Fortune 500 corporate board seats at a time when women held over $50 \%$ of the managerial positions. In addition, only $15.7 \%$ of these companies had women in corporate office leadership positions. ${ }^{24}$

\section{What are the numbers for women in CEO positions in US hospitals?}

According to the 2010 data from the Bureau of Labor Statistics, hospitals employ 6,249,000 workers total, and $76.5 \%$ of these are women. ${ }^{25}$ Among 7,805,000 health care practitioners and technical workers, $74.3 \%$ are female. ${ }^{26}$ In this female-dominated industry, how are women represented in the CEO positions?

The 2010 Bureau of Labor Statistics data show that women hold $25.5 \%$ of CEO positions nationally for all types of business. It shows general and operational managers at $29.9 \%$ for women in all types of business. ${ }^{25}$ Gender-specific information on women hospital CEOs is not available through the Bureau of Labor Statistics.

In health care, the stronghold for women in administrator/ CEO positions has in the past been in religiously affiliated hospitals. According to the Catholic Health Association of the United States, women in hospital CEO positions in the past were religious women. Their numbers have dramatically declined; $91 \%$ of religious women are over 60 years. The number of female religious administrators/CEOs in Catholic hospitals declined from "770 in 1968 to 13 in 2009, while lay administrators/CEO increased from 26 to 611 ". ${ }^{27}$

The American College of Healthcare Executives has compared career attainment by men and women since 1990 . The most recent report in 2006 shows an "increase in the proportion of women relative to men who achieve CEO status. . . They achieved CEO positions at $63 \%$ of the male rate". ${ }^{28}$ The report goes on to say that women in health care are earning $18 \%$ less overall, "women in health care management are in a better relative position than women in general business who in 2005 earned $27 \%$ less than men".

The 2006 American College of Healthcare Executives report states that "having attained equal levels of education and experience in 2005, women on average earned $\$ 107,800$ and men on average earned $\$ 131,000 " .{ }^{28}$ The Bureau of Labor Statistics information on salary for all hospital CEOs for 2009 showed an annual mean wage of $\$ 180,490 .{ }^{29}$ This information can be viewed as a positive for women in health care as setting the tone for the nation of women in business in CEO positions and viewed as a continued struggle for a female-dominated profession to achieve CEO positions.

To determine if the percentage of women in US hospital CEO positions has changed, Internet and phone surveys were conducted to identify women in hospital CEO positions in Washington State. Additionally, the Thomson Reuters 2011 Top 100 hospitals was used to determine the national numbers for women. ${ }^{30}$ Further, the list was broken into smaller groups to look at Everest Award hospitals, major teaching hospitals, teaching hospitals, and large, and medium and small community hospitals from the Top 100 list.

For the Washington State survey, a list from the Washington State Hospital Association was used which showed 21 female CEOs of 116 organizations. Thus, 18\% of the CEOs were women in Washington State health care organizations. It is noted that there are no Washington State hospitals in the Thomson Reuters 2011 Top 100 hospital list. The overall Thomson Reuters 2011 Top 100 hospital list showed women as CEOs at $12 \%$. In breaking the list down further, the following results emerged from the Top 100 list. In Everest Award hospitals, the ratio of male and female CEOs was at 50\%. Everest Award hospitals are hospitals that have the highest current performance and the fastest long-term improvement. Hospitals that win this award are setting national benchmarks for both long-term improvement and top 1-year performance. ${ }^{30}$ There are six Everest Award winners in the Top 100 list.

Table 2 shows that those hospitals setting the benchmarks for the country are showing women at the highest ratio seen in the literature. From the remaining categories of the Top 100 hospitals, large community hospitals show the largest percentage of women as CEOs.

\section{Reasons for gender imbalance}

The demand for significant change and strong leadership to guide necessary health care transformation is strong and pervasive. ${ }^{31}$ Establishing gender balance within the top

Table 2 Thomson Reuters 201 I Top 100 hospitals

\begin{tabular}{lll}
\hline Category & $\begin{array}{l}\text { \% of women } \\
\text { as CEOs }\end{array}$ & Hospitals (n) \\
\hline Everest award & 50 & 6 \\
Major teaching hospitals & 7 & 15 \\
Teaching hospitals & 4 & 25 \\
Large community hospitals & 25 & 20 \\
Medium community hospitals & 10 & 20 \\
Small community hospitals & 5 & 20 \\
\hline
\end{tabular}


tier of health care leadership is likely to be an important contributor to innovation and effectiveness within the health care industry.

Although women have gained ground on gender equality issues like discrimination and harassment, ${ }^{32}$ these structural changes alone have been insufficient to address the dual challenges of career development and access to leadership positions. The reasons for gender imbalance in health care leadership are multifaceted and may include:

- Management structure and leadership bias that favor a masculine style

- Lack of appreciation of the value of gender differences in building a diverse culture with improved organizational performance

- Individual barriers that thwart the ambition of women leaders and drive away future leaders

- Absence of a strategic focus and dedicated resources to address the gender imbalance.

The health care industry has evolved from a historic leadership model that is bureaucratic and hierarchical, akin to that of a manufacturing plant. Today's hospitals are organized and operated in essentially the same way they were 50 years ago. ${ }^{33}$ It is no surprise that the preferred leadership style favors the traditional command-and-control leader. Masculine leadership traits associated with this style include competition, assertiveness, and decisive action, ${ }^{18}$ while characteristics strongly associated with women such as modesty, cooperation, and emotiveness, are often seen as incompatible with strong leadership, particularly in an industry with a historic reliance on command-and-control. ${ }^{34}$ The positive bias toward male leaders provides them with opportunities for success, and less favorable perceptions of women's roles and abilities may result in women being excluded from access to similar opportunities. $^{35}$

Experts from various disciplines have studied gender differences that contribute to or account for distinctions in leadership qualities and styles. Scientists who study the relationship between brain structure and function point to differences in the way the brains of women and men process language, emotion, information, and cognition. ${ }^{36,37}$ Such differences may be attributed to women's more highly developed verbal skills, empathy, and social skills, while qualities such as assertiveness, achievement orientation, and independence are more commonly associated with men. Acknowledging these differences between women and men is an essential component of organizational development and performance, and deconstructing existing barriers is a critical step to addressing gender imbalance in health care. ${ }^{38}$
Table 3 Characteristics of successful executives

\begin{tabular}{ll}
\hline Title & Characteristic \\
\hline Agent of change & $\begin{array}{l}\text { Inspirational, risk-taker, energetic, decisive, } \\
\text { persuasive } \\
\text { Managerial courage }\end{array}$ \\
$\begin{array}{l}\text { Courageous, learns from adversity, resilient, } \\
\text { resourceful } \\
\text { Intelligent, team builder, well-informed, } \\
\text { veadership ability }\end{array}$ & $\begin{array}{l}\text { Proactive, industrious, politically astute, } \\
\text { action-oriented and achievement-oriented }\end{array}$ \\
\hline
\end{tabular}

Incorporating feminine or transformational qualities such as collaboration, teamwork, and information sharing into what currently is a masculine-dominated leadership style provides new avenues for growth and development. Health care's dependence on the masculine leadership style with its penchant for finding quick answers, completing tasks, and being decisive may limit access to feminine-centered traits of integrating and synthesizing inter-related factors. ${ }^{39}$ By rebalancing the masculine and feminine within health care leadership, we have greater opportunity to improve organizational performance.

Neither male nor female traits are more highly correlated with effective leadership, according to Eagly and Carli. They conclude that women and men "differ little in the traits that are most important to leadership." 18 The characteristics they ascribed to successful executives are shown in Table 3.

The Kellogg Executive Women's Network report on a study of its members explores the barriers that have contributed to or resulted in gender imbalance among the ranks of top executives. These data, identified in Table 4, enumerate the multiple barriers that limit the success of female leaders. ${ }^{38}$ These factors may inordinately impact female leaders and their ability to advance to top executive positions in proportion to their male counterparts. Due to the depth and breadth of these barriers, women operating individually or independently will not be able to alter the direction of health care leadership. Results from the McKinsey Global Survey ${ }^{40}$ demonstrate a direct connection between a company's financial performance and its gender diversity, which highlights

Table 4 Barriers limiting success of female leaders

Barriers
Glass ceiling
Lack of role models
Perception including stereotypes that favor male leaders
Lack of confidence and female insecurities that limit the ability of women
to achieve a balance between aggressiveness and appeasement
The old boys club
Work life balance


Table 5 Actions to remove barriers to gender imbalance

\section{Actions}

Awareness or concerns for gender diversity as a critical matter

Target setting and implementation objectives

Commitment from chief executive officer and top management

Dedicated resources

Knowledge of best practices for gender diversity

Transparency about company performance on gender diversity issues

the strategic, industry-wide importance of gender diversity. A strategic action plan to remove barriers identified in the McKinsey Survey and address gender imbalance must include the actions identified in Table 5.

The same survey offered potential interventions based on an assessment of those with the greatest impact on increasing gender diversity. These interventions were:

- Visible monitoring of gender diversity programs by the CEO and top management

- Flexible working conditions and location

- Programs to reconcile work and family life

- Mentoring of junior women by senior executives

- Programs encouraging female networking and role models.

\section{Addressing the imbalance}

Initiatives to address the gender imbalances in health care are not new but need critical mass and focus to be effective. The use of mentors, male sponsors, and networking are examples of programs that can make a difference but only if done in concert with consistent and rigorous support from executive leadership. Corporations (and their CEOs) as well as individuals must endorse new initiatives. Since the changes that need to take place are of a cultural nature, both stakeholders should be on board to be effective.

\section{Individual initiatives to address gender imbalance}

It is important for women to embrace initiatives personally that will help promote their career advancement. Women need to take responsibility for their career paths in order to overcome the many obstacles that exist in the corporate world, as well as the barriers that women often put upon themselves.

A feminine style of leadership is a strong suit in today's highly connected world, which depends upon relationships and effective communications for success. The McKinsey partners conducted a study of highly successful women leaders to identify what attributes they had that contributed to their achievements. ${ }^{41}$
The commonalities among these highly successful leaders were their passion and meaning for their work, their ability to sustain energy that is the life force of change, converting emotions such as fear and stress into opportunity, acting in the face of risk, and their ability to positively connect with others. This collection of attributes makes up a model of centered leadership. Women have many of these natural talents and should work to strengthen them so that their leadership abilities can be utilized in influential executive positions.

Networking and mentoring are vital initiatives for women to leverage their community connections and strengthen their leadership skills with advice and insights from other more seasoned leaders. It is important to note that mentoring and networking is predominantly the domain of the individual. Although others will be needed to make the connections work, the individual needs to be the initiator of these activities and be responsible for their own career advancement.

Although women have many natural leadership talents, many are "accidental leaders" and not realizing their strengths until others identify them. Many women experience self-esteem issues that impede their ability to pursue leadership opportunities or lead effectively in maledominated environments. Stereotypes about leaders often impact women's ability to function effectively in the face of bias and prejudices against female leaders. ${ }^{18}$ One study of young women leaders demonstrated many discriminatory factors that impede their ability to lead effectively. ${ }^{20} \mathrm{~A}$ circular and reinforcing cycle of uncertainty and insecurity existed as the young leaders dealt with these biases and prejudices as leaders. Becoming aware of these issues and dealing with them directly can be empowering for women and constitute an opportunity for women to overcome such embedded cultural factors. An example of this would be for women to promote themselves more as competent leaders, in much the way men have done for years. Displays of self confidence reinforce leadership abilities and open avenues for new opportunities.

The gender imbalance in leadership positions has persisted for some time, but there is an increasing awareness of the importance of women supporting other women in pursuit of career advancement. The baby-boomer generation has a great opportunity to share their experiential learning with the next generation of leaders so they can experience optimal career advancement. This support can take place in the workplace, in professional organizations, or other networking settings. The earlier generation of women leaders demonstrated perseverance and resilience. The insights that these pioneers gained from their experiences can greatly assist the up-and- 
coming leaders who often do not anticipate the barriers and biases that continue to be present in the workplace.

\section{Corporate initiatives to address gender imbalance}

Corporations are beginning to realize that women are a valuable resource in the search for talent to lead into the future. Some corporations are addressing the cultural workplace issues by developing more opportunities for female leaders, creating more flexible work schedules, creating leadership development programs, organizing mentoring programs, and forming corporate women networks. A prominent example of this cultural transformation is the work done at Deloitte to move away from the corporate ladder to a corporate lattice concept. ${ }^{42}$ The lattice concept incorporates the new model of work that incorporates both the professional and personal goals of the individual and supports multidimensional career paths, high workforce mobility, and continuing career opportunities. Such corporate flexibility is advantageous for both genders but in particular moves away from the penalization women have often suffered from when they temporarily digress from a career focus to balance family and work-life needs. Those types of diversions and the opportunity to experience new work skills no longer prevents the individual from attaining higher levels of responsibility in the future.

Deloitte experienced many benefits by moving to this new corporate model, including retention of high-performing female talent, increased teamwork and collaboration, greater diversity of leadership, and other corporate benefits, such as improved financial performance.

Another corporate strategy that assists women in their career advancement is supporting women in leadership positions that have bottom line profit-and-loss impact. Often women are only promoted in support positions, such as human resources, planning, or marketing, a limitation that prevents eligibility for corporate-level executive positions. The Wall Street Journal recently convened a summit of almost 200 top leaders in government, business, and academia to discuss why women in America's workplace are falling back instead of making gains and to develop an action plan to address the issues. ${ }^{43}$ One of the major recommendations of this executive task force was that companies should make it possible for women to break out of support positions, gain experience with revenue generation, and master the core of the business so that they can pursue higher executive positions.

Other corporate recommendations from this summit included basing promotion decisions on women's potential, changing corporate cultures (eg, with leadership development programs that provide deliberate, long-term focus on women), and creating accountability at the CEO and board level to promote women at the top. A CEO commission was recommended from leading companies to identify, drive, and publish results of efforts to increase numbers of women at the top. Targets would be set to advance women in senior management positions, and metrics and score cards would be published to ensure accountability.

Another important place that women are missing is on corporate boards. The number of women on corporate boards is $15 \%$ of Fortune 500 board director positions, which has changed relatively little in over a decade. ${ }^{44}$ Corporate boards can benefit from diversity of thought, but women have not been given the opportunity to break into this realm of important decision-making influence. While countries such as Norway and Spain have set quotas for gender diversity on public boards, the US and other countries have not, and the numbers of women on boards remain low. This is another opportunity for boards

Table 6 Initiatives to address gender imbalance

\begin{tabular}{lll}
\hline Strategy & Individual leader & Corporations/chief executive officer \\
\hline Develop-centered leadership skills & $\checkmark$ & $\checkmark$ \\
Networking and mentoring & $\checkmark$ & $\checkmark$ \\
Women supporting women & $\checkmark$ & $\checkmark$ \\
Self-promotion and strong sense of self & & $\checkmark$ \\
Assist next-generation leaders & & $\checkmark$ \\
Corporate culture changes & & $\checkmark$ \\
Flexible work schedules & & $\checkmark$ \\
Career advancement opportunities & & $\checkmark$ \\
Leadership development/talent programs & & $\checkmark$ \\
Profit-and-loss roles for women & & $\checkmark$ \\
Metrics to measure success & & \\
Board opportunities for women & & \\
\hline
\end{tabular}


Table 7 Top recommendations

Top 5 Recommendations for corporations in advancing women Profit-and-loss leadership roles for women

Leverage $\mathrm{C}$-suite power by holding CEO accountable for inclusion

of women

Promote women on potential

Mentors and sponsors

Strong talent management programs

Wall Street Journal, Women in the Economy Executive Task Force, April II, 20II

and CEOs to set standards for board gender diversity and measure results.

Both individual women leaders and corporations led by CEOs and governing boards who commit to accountability in supporting the advancement of women to top positions can make a difference in moving women from the stalled position they are currently experiencing in the workplace. A focused collective effort is needed so that the positive influence of female leadership can become a competitive advantage for companies to succeed. These issues are identified in Tables 6 and 7.

\section{Summary}

It is clear that gender disparity exists in health care leadership. Many reasons for this have been presented, including a management bias that favors a masculine style, lack of appreciation of the value of gender differences, and absence of a strategic focus and dedicated resources to address the gender imbalance. Initiatives both at the individual and corporate levels are suggested to address this imbalance. Simply put, the status of women rising in the ranks in health care leadership in CEO positions has not changed in the past three decades. For the numbers of women working in the health care workforce, their numbers are not represented adequately at the CEO level.

Without dedicated efforts, change in these numbers will not occur. Much has been written regarding this issue, but little has been done to achieve a significant improvement. The transformational leadership approach used by women needs to be recognized as beneficial and critical in redesigning health care organizations in these challenging and ever changing times.

\section{Disclosure}

The authors report no conflicts of interest in this work.

\section{References}

1. Kalisch PA, Kalisch BJ. The Advance of American Nursing. 1st ed. Boston, MA: Little, Brown and Company; 1978.

2. McDonagh KJ. Leadership in a new healthcare world. Semin Nurse Manag. 1997;5:106-110.
3. Tye J. The mother of all hospital administrators. Available from: http://www.hhnmag.com/hhnmag/HHNDaily/HHNDailyDisplay. dhtml?id=5900002469. Accessed October 15, 2011.

4. Ehrenreich B, English D. For Her Own Good: 150 Years of the Experts' Advice to Women. New York: Anchor Books Doubleday; 1978.

5. Lantz PM. Gender and leadership in healthcare administration: 21st century progress and challenges. J Healthc Manag. 2008;53: 291-303.

6. Denmark FL. Women, leadership and empowerment. Psychol Women. 1993; 17:343-356.

7. Parker B, Fagenson EA. An Introductory Overview of Women in Corporate Management. Women in Management: Current Research Issues. London, UK: Sage; 1994.

8. Schein VE. A global look at psychological barriers to women's progress in management. $J$ Soc Issues. 2001;57:675-688.

9. Lewin K, Lippitt R. An experimental approach to the study of autocracy and democracy: a preliminary note. Sociometry. 1938;1: 292-300.

10. Blake RR, Mouton JS. The Managerial Grid. Houston, TX: Gulf Publishing; 1964.

11. Powell GN. Reflections on the glass ceiling: recent trends and future prospects. In: Powell GN, editor. Handbook of Gender and Work. Newbury Park, CA: Sage Publications; 1999.

12. Jogulu UD, Wood GJ. The role of leadership theory in raising the profile of women in management. Equal Opport Int. 2006;25:4.

13. Eagly AH, Karau SJ. Gender and emergence of leaders: a meta analysis. J Pers Soc Psychol. 1991;60:685-710.

14. Lowe KB, Kroeck KG, Sivasubramaniam N. Effectiveness correlates of transformational and transactional leadership: a meta-analytic review of the MLQ literature. Leadership Quart. 1996;7:385-426.

15. Seltzer J, Bass B. Transformation leadership: beyond initiation and consideration. J Manage. 1990;16:693-703.

16. Eagly AH, Johnson BT. Gender and leadership style: a meta analysis Psychol Bull. 1990;108:233-256.

17. Bass B. Does the transactional-transformational leadership paradigm transcend organizational and national boundaries? Am Psychol. 1997;52:130-139.

18. Eagly AH, Carli LL. Through the labyrinth: the truth about how women become leaders. Harvard Bus School Press. 2007:127-129.

19. Aud S, Hussar W, Kena G, et al. The Condition of Education 2011. Washington, DC: US Department of Education, National Center for Educational Statistics, Government Printing Office; 2011.

20. McEldowney RP, Bobrowski P, Gramberg A. Factors affecting the next generation of women leaders: mapping the challenges, antecedents, and consequences of effective leadership. J Leadership Stud. 2009;3:24-30.

21. Burke RJ, Cooper CL. Leading in Turbulent Times: Managing in the New World of Work. Malden, MA: Blackwell Publishing; 2004.

22. Catalyst 2008. Catalyst Census of Women Corporate Officers and Top Earners of the Fortune 500. Available from: http://www.catalyst.org/ publication/283/2008-catalyst-census-of-women-corporate-officersand-top-earners-of-the-fortune-500. Accessed October 15, 2011.

23. Eagly AH, Carli LL. The female leadership advantage: an evaluation of the evidence. Leadership Quart. 2003;14:807-834.

24. Omar A, Davidson JJ. Women in management: A comparative crosscultural overview. IJCCM. 2001;8:35-67.

25. Bureau of Labor Statistics. Occupational employment and wages, May 2009. Employed persons by detailed occupation. Available from: http://www.bls.gov/oes/2009/may/oes291125.htm. Accessed October $15,2011$.

26. Bureau of Labor Statistics. Occupational Employment Statistics: Overview. Available from: http://www.bls.gov/oes/oes_emp.htm. Accessed October 15, 2011.

27. Bauer E. Let's look ahead, prepare for trends. Health Prog. 2010;91:6-7.

28. American College of Healthcare Executives. A Comparison of the Career Attainments of Men and Women Healthcare Executives. Dec 2006. Available from: http://www.ache.org/pubs/research/gender_ study_full_report.pdf. Accessed October 15, 2011. 
29. Bureau of Labor Statistics. Occupational employment and wages, May 2009. Available from: http://www.bls.gov/oes/2009/may/oes291125. htm. Accessed October 15, 2011.

30. Thomson Reuters. 100 Top Hospitals: Study Overview and Research Findings. 18th ed. March 28, 2011.

31. Lantz PM. Gender and leadership in healthcare administration: 21 st century progress and challenges. J Healthc Manag. 2008;53:291-303.

32. Bain and Company. The great disappearing act/gender parity up the corporate ladder. Jan 2010. Available from: http://www.bain.com/ publications/articles/the-great-disappearing-act-gender-parity-up-thecorporate-ladder.aspx. Accessed October 15, 2011.

33. Beckham D. CEOs under scrutiny. Available from: http://www.hhnmag. com/hhnmag/HHNDaily/HHNDailyDisplay.dhtml?id=6890007167. Accessed October 15, 2011.

34. Sounart A. Rising to the Top: AMN Healthcare helps women break through the glass ceiling. AMN Healthcare. Available from: http:// www.amnhealthcare.com/News/news-details.aspx?Id=7152. Accessed October 15, 2011.

35. Hoss MA. Women in hospital chief executive officer positions: fact or fiction. Advancing Women. 2006. Available from: http:// www.advancingwomen.com/awl/summer2006/Hoss.html. Accessed October 15, 2011.

36. Witelson S. It's partly in your head. 2011. Available from: http://online. wsj.com/article/SB10001424052748704013604576246612976236624. html. Accessed October 15, 2011.
37. Sabbatini R. Are there differences in the brains of males and females? Available from: http://www.cerebromente.org.br/n11/mente/eisntein/ cerebro-homens.html. Accessed October 15, 2011.

38. Kellogg Executive Women's Network. Developing Women Leaders. 2011.

39. Caprino K. Mandating women at the leadership table: why the time is now. Forbes.com. March 25, 2011. Available at: http://www.forbes.com/ sites/85broads/2011/03/25/mandating-women-at-the-leadership-tablewhy-the-time-is-now. Accessed October 26, 2011.

40. McKinsey Global Survey Results. Moving Women to the Top. 2010. Available from: http://www.mckinseyquarterly.com/Moving_women_ to_the_top_McKinsey_Global_Survey_results_2686. Accessed October 15, 2011.

41. Barsh J, Cranston S, Lewis G. How Remarkable Women Lead: The Breakthrough Model for Work and Life. New York: Crown Business, Random House; 2009.

42. Benko C, Anderson M. The Corporate Lattice: Achieving High Performance in the Changing World of Work. Boston, MA: Harvard Business Review Press; 2010.

43. Blumenstein R. A blueprint for change. Wall Street Journal. April 11, 2011.

44. Catalyst. 2010 Catalyst Census: Fortune 500 Women Board Directors. December 2010. Available from: http://catalyst.org/ publication/460/2010-catalyst-census-fortune-500-women-boarddirectors. Accessed October 15, 2011.
Journal of Healthcare Leadership

\section{Publish your work in this journal}

The Journal of Healthcare Leadership is an international, peer-reviewed, open access journal focusing on leadership for the health profession. The journal is committed to the rapid publication of research focusing on but not limited to: Healthcare policy and law; Theoretical and practical aspects healthcare delivery; Interactions between healthcare and society and evidence-based practices;

\section{Dovepress}

Interdisciplinary decision-making; Philosophical and ethical issues; Hazard management; Research and opinion for health leadership; Leadership assessment. The manuscript management system is completely online and includes a very quick and fair peer-review system. Visit http://www.dovepress.com/ testimonials.php to read real quotes from published authors. 